\title{
Intertextualidades \\ Freud, Hegel e Husserl na constituição da teoria da consciência-texto de Paul Ricoeur
}

Fernanda Henriques

\author{
À memória de João Paisana, \\ recordando a sua grande humanidade \\ e o seu sentido da pessoa do outro.
}

Desde que Michel Philibert' ${ }^{1}$ criou a imagem do tríptico para explicar a tessitura textual de Paul Ricoeur - querendo com ela salientar que este autor lê sempre qualquer texto ou autor a partir de um outro texto ou de um outro autor-, que tal imagem pode ser tida como um lugar comum na abordagem da textualidade ricoeuriana.

No caso vertente, em que me proponho analisar a teoria da consciência-texto ou consciência-tarefa que Ricoeur leva a cabo na sua obra sobre Freud, de $1965^{2}$, a imagem de Philibert, embora pertinente, mostra-se insuficiente, na medida em que essa teoria resulta da articulação de vários trípticos. Diria que, pelo menos, quatro. Por um lado, um tríptico duplo e simétrico em que Freud e Hegel são lidos, cada um deles a partir e em confronto com o outro. Por outro lado, quer a leitura de Freud quer a de Hegel são possibilitadas por uma leitura anterior de Husserl. Nesta perspectiva, a teoria da consciência-texto ou consciência-tarefa resulta de uma intertextualidade complexa na qual Freud e Hegel desempenham o papel de hermenêuticas rivais, protagonizando o conflito interpretativo, e Husserl funciona como o possibilitador do próprio exercício hermenêutico, fornecendo o seu solo legitimador.

É esta tessitura, constituída de trípticos cruzados, que me proponho explicitar no presente texto.

1 Cf. Michel PHILIBERT, Paul Ricoeur ou la liberté selon l'espérance, Paris, Éditions Seghers, 1971.

2 Paul RICOEUR, De l'interprétation. Essai sur Freud, Paris, Éditions du Seuil, 1965. 


\section{O sentido da obra sobre Freud no conjunto da filosofia ricoeuriana}

Não obstante determinantes circunstanciais terem feito com que a produção escrita de Ricoeur sobre Freud não tenha prosseguido, de modo sistemático, depois do seu grande texto de $1965^{3}$, esta obra não só não é episódica no conjunto do seu pensar, como representa mesmo um momento decisivo do seu desenvolvimento.

Em Refléxion faite, a sua auto-biografia intelectual, Ricoeur, apreciando a evolução do seu pensamento nos anos 60, afirma que é no livro sobre Freud que se faz um primeiro balanço dessa evolução e da transformação da sua perspectiva acerca do âmbito próprio de uma filosofia reflexiva ${ }^{4}$. As considerações de Paul Ricoeur revelam a consciência que o filósofo tem da importância da passagem pela psicanálise na elaboração da especificidade da sua concepção hermenêutica, nomeadamente, no que se refere ao conceito de Conflito de Interpretações, bem como o papel determinante que o diálogo com Freud ocupa na abordagem do Cogito ferido que, desde Le volontaire et l'involontaire até Soi-même comme un autre, pode ser tomado como o horizonte referencial da sua meditação filosóficas.

Na verdade, é no Essai sur Freud que fica tematizado e teorizado um conceito de subjectividade que, por um lado, reafirma a posição trabalhada em Le volontaire et l'involontaire e, por outro, a projecta num novo quadro de análise:

"Essas conclusões [as do final de Le volontaire et l'involontaire], ratifico-as ainda hoje; mas ultrapasso-as num ponto decisivo, exactamente aquele que originou toda a pesquisa deste livro.

Um método hermenêutico, acoplado à reflexão, vai muito mais longe que um método eidético, como eu praticava então: a'dependência do Cogito em relação à posição do desejo não é directamente captada através da experiência imediata, mas interpretada por uma outra consciência, através dos sinais, aparentemente sem sentido, oferecidos à interlocução. (...) O enraizamento da reflexão na vida só a título de verdade hermenêutica é ele próprio compreendido pela consciência reflexiva"6.

Ou seja, a quase 20 anos da apresentação do projecto da Filosofia da Vontade, e depois de.já ter publicado a segunda parte desse projecto onde, pela primeira vez, desenvolve uma prática hermenêutica ${ }^{7}$, é, no entanto, no processo de

3 Cf. Paul RICOEUR Réflexion faite, Paris, Éditions Esprit, 1995, p. 37. Na sua grande obra sobre Paul Ricoeur - François DOSSE, Paul Ricoeur: Les sens d'une vie, Paris, Éditions La Découverte, 1997 - Dosse faz uma análise da controvérsia, insultuosa para Ricoeur, que contextualizou a recepção da obra de Ricoeur sobre Freud, de que foram protagonistas Lacan e alguns dos seus discípulos.

4 Cf. Paul RICOEUR, Réflexion faite, pp. 34-38.

5 Paul RICOEUR, Le volontaire et l'involontaire, Paris, Aubier-Montaigne, 1950; Soi-même comme un autre, Paris, Éditions du Seuil, 1990.

6 Paul RICOEUR, De l'interprétation. Essai sur Freud, p. 443.

7 O projecto da Filosofia da Vontade, tal como Ricoeur o apresenta em Le volontaire et l'involontaire, compreende 3 momentos: uma eidética, uma empírica e uma poética da vontade. Le volontaire et l'involontaire corresponde ao trabalho do primeiro momento desse projecto e, em 1960, Ricoeur publica, na editora Aubier-Montaigne, duas obras L'Homme faillible, e La symbolique du mal - que, sob a designação geral de Finitude 
se confrontar com o pensamento de Freud, que Ricoeur configura os recursos possibilitadores a partir dos quais, no início dos anos 90, pode desenvolver, em Soi-même comme un autre, uma hermenêutica do si-mesmo, que se situa no espaço que define o intervalo entre um Cogito exaltado e um Cogito negado, ou, nas suas palavras: “(...) se encontra a igual distância da apologia do Cogito e da sua destituição"s.

Do meu ponto de vista, o fundamento desses recursos possibillitadores corresponde à definição de uma teoria da subjectividade concebida como o resultado de uma dialéctica entre um princípio regressivo, determinador, um arquê e um princípio progressivo, libertador, um telos, de cuja interacção resulta a textualidade da consciência, disponível para o jogo de uma hermenêutica conflitual. Por esta via fica decisivamente estabelecido na obra sobre Freud, de 1965, a primeira interpretação do Cogito ferido, isto é, de um Cogito que, assumindo-se, embora, como ponto de partida da reflexão se reconhece, no mesmo gesto, impotente como fonte última do sentido, negando-se, por isso, como princípio fundante 9 . Trata-se, no fundo, de tematizar, de forma sistemática e alargada, a ideia de uma aceitação limitada do Cogito, que corresponde à posição de princípio da filosofia reflexiva de Paul Ricoeur, tendo sido explicitada desde Le volontaire et l'involontaire. Efectivamente, a noção de consciência, subjacente a esta primeira obra do projecto filosófico ricoeuriano, é a de uma consciência cindida, na medida em que, por um lado, tal projecto parte de um Cogito tomado como intrinsecamente incoincidente e, por outro, propõe-se a sua reconquista integral. No conjunto do projecto da Filosofia da Vontade, como séu primeiro momento, Le volontaire et l'involontaire corresponde à definição das suas condições de possibilidade sendo, como diz Ricoeur, os seus prolegómenos e assumindo a figura de um quadro teórico geral de inteligibilidade de uma reflexão sobre a subjectividade incarnada.

O segundo momento da Filosofia da Vontade é apresentado pelo autor como uma Empírica, abrindo uma nova problemática e uma nova metodologia. Esta nova problemática decorre da análise da natureza lábil do ser humano, definindo a estrutura ontológica deste como uma estrutura mediadora. O ser humano é uma estrutura intermediária em relação a si mesmo porque é um ser cuja natureza consiste na incoincidência consigo próprio. De alguma maneira, Essai sur Freud corresponde a outra aproximação metodológica desta mesma questão ${ }^{10}$, equivalendo a um processo de purificação da reflexão, desempenhando a psicanálise a dimensão de calvário ou prova.

Deste modo, o trabalho que Ricoeur elabora em Essai sur Freud pode ser lido como uma resposta à problemática da crise da consciência levantada com o

et culpabilité, correspondem à realização parcial do segundo momento do mesmo projecto. Quanto ao seu terceiro momento, como tal, Ricoeur não chegou ainda a publicá-lo. Em Réflexion faite Paul Ricoeur faz uma apreciação crítica, quer ao desenho quer à realização do seu projecto.

8 Paul RICOEUR, Soi-même comme un autre, p. 15.

9 Este ponto de vista não significa ignorar Le volontaire et l'involontaire, mas equivale a considerar que em Le volontaire et l'involontaire se parte da ideia de um Cogito ferido e se mostra como ele funciona ao nível da vontade. É em Essai sur Freud que se tematiza, do ponto de vista do conteúdo, o Cogito ferido. Nesta perspectiva, a segunda teorização do Cogito ferido corresponde à temática da identidade narrativa, categoria produzida no contexto da trilogia Temps et récit, Paris, Éditions du Seuil, 1983, 1984, 1985.

10 Don IHDE, na sua obra sobre Paul Ricoeur: Hermeneutic Phenomenology. The philosophy of Paul Ricoeur, Evanston, Northwestern University Press, 1971, defende, também, a aproximação da obra sobre Freud ao momento da empírica da vontade, no quadro da sua tese de que não há ruptura entre a fenomenologia e a hermenêutica, em Paul Ricoeur. 
aparecimento, no campo teórico da figura da consciênciạ falsa ${ }^{11}$, que ele considera ser o repto que um filósofo, cuja formação radica basicamente na tradição fenomenológica, tem, necessariamente, de aceitar ${ }^{12}$.

Com a designação de crítica da consciência falsa Ricoeur pretende recobrir as posições de Marx, Nietzsche e Freud impondo-se-lhe, como necessidade cultural do nosso tempo, a empresa de pensar o sentido concorrente dessas três hermenêuticas, enquanto hermenêuticas desmistificadoras, tarefa que teria um resultado mais proficuo para a evolução do pensar contemporâneo do que a procura e o estabelecimento das suas diferenças ${ }^{13}$. O seu denominador comum é a dúvida sobre a consciência, ou seja, o ataque à imediatez da consciência de si. Diz, explicitamente, Ricoeur:

"A categoria fundamental da consciência, para os três, é a relação escondido-mostrado ou, se se prefere dissimulado-expresso"14.

No entanto, do seu ponto de vista, essa crítica da consciência imediata é feita no sentido do restabelecimento de uma forma de saber mais autêntica, mediante o desenvolvimento de um comportamento metodológico constituído pela interpretação:

\begin{abstract}
"Ora, os três abrem o horizonte em ordem a uma palavra mais autêntica, em ordem a um novo reino da verdade, não apenas por meio de uma crítica "destrutiva", mas pela invenção de um acto de interpretar. Descartes triunfa da dúvida sobre a coisa pela evidência da consciência; eles triunfam da dúvida sobre a consciência através de uma exegese do sentido. A partir deles, a compreensão é uma hermenêutica: a partir de agora, procurar o sentido já não é escavar a consciência do sentido, mas decifrar as suas expressões"15.
\end{abstract}

11 Este tema é central nos textos de Ricoeur; ao registo teórico das verdades sem sujeito ele pretende contrapor o sentido de uma filosofia reflexiva. São particularmente relevantes da sua posição, para além do seu Essai sur Freud, os artigos de Le Conflit des Interprétations, Paris, Éditions du Seuil, 1969, especialmente, "La question du sujet: le défi de la semiologie", pp. 233-262, onde o autor dialoga com as críticas de Freud e as do estruturalismo, procurando estabelecer a legitimidade e a necessidade de se pensar o sujeito, não contra aqueles registos críticos, mas partindo deles.

Muitos estudos sobre Paul Ricoeur são realizados tendo em conta a problemática do sujeito. Destacaria de entre eles alguns que se podem constituir como pontos de referência, em virtude do nó problemático que privilegiam:

- Domenico JERVOLINO, The Cogito and Hermeneutics: The question of the Subject in Ricoeur, Dordrecht-Boston-London, Kluwer Academic Publishers, 1990.

-Páll SKÚLASON, Le cercle du sujet dans la philosophie de Paul Ricoeur, Paris, L'Harmattan, 2001.

- Sean P. O'CONNELL, Man as intermediate: an examination of Paul Ricoeur's philosophical anthropology and its implications with respect to philosophical, Ann Arbor, University Microfilms International, 1987.

- Theoneste NKERAMIHIGO, L'Homme et la Transcendance selon Paul Ricoeur, Paris, Lethielleux, 1984.

12 É este o sentido de toda a introdução ao artigo "Herméneutique et psychanalyse", in Le Conflit des Interprétations, pp. 101-207.

13 Cf. Ibidem, p. 148 e 151.

14 Cf. Ibidem, p. 149.

is Cf. Ibidem, p. 149. 
Ricoeur faz, pois, uma interpretação positiva da dimensão de suspeita das práticas de Marx, Nietzsche e Freud, explicitando que aqueles autores não só não destroem a consciência como a pretendem alargar, na medida em que a sua crítica à imediatez da consciência, como ilusão de saber, destrói, de facto, a consciência como dado, mas para fazer emergir a possibilidade de a repensar, a partir dessa destruição, através da prática metodológica da interpretação. No fundo, ele quer realçar que o resultado do confronto com as hermenêticas da suspeita se traduz no reconhecimento da necessidade de mediação no acesso ao saber de si mesmo.

É esta interpretação conjunta dos três pensadores da suspeita que fornece a chave de compreensão do trabalho que Ricoeur se propõe realizar na sua grande obra sobre Freud, através de cujo diálogo quer repensar a problemática da subjectividade, para constituir um conceito de consciência que possa ter o inconsciente como seu outro. Do confronto com a crítica psicanalítica da consciência Ricoeur configurará a sua ideia de consciência-tarefa ou consciência-texto, cujos contornos teóricos se dimensionam por dois parâmetros:

A consciência não pode mais ser tomada como o lugar de origem do sentido; pelo contrário, aceitar que o inconsciente é o seu outro equivale a considerá-la no termo de um processo de organização do sentido e não como sua fonte imediata. Assim, ser consciente passa a significar tornar-se consciente, ou seja, de dado converte-se em processo.

A configuração da consciência-tarefa arrasta a necessidade de uma metodologia que equivalha a uma estrutura de mediação exegética. Ou seja, pensar a consciência como uma figura terminal obriga à definição de um processo mediador possibilitante do acesso ao saber de si dessa consciência.

Assim, em Essai sur Freud, a temática da consciência-tarefa ou consciência-texto é tratada através dos temas do esquecimento e da separação.

$\mathrm{O}$ sentido de si, do sujeito, está perdido para si, esquecido. Chegar à consciência de si, como saber verdadeiro, vai ter de ser um processo de recuperação. Ou seja, o sentido da minha vida só me é acessível por uma interpretação que, assim, se configura em estrutura mediadora. Essa recuperação do esquecido, do distante, pelo qual o sujeito tem acesso ao sentido do seu existir, faz-se, no campo da objectividade, através da interpretação das produções culturais.

Sintetizando, aquilo que emerge como a definição da natureza crítica da consciência é a sua desadequação ou incoincidência. Ou seja, é a sua natureza cindida, sendo a partir desta natureza que se desenha a necessidade da estrutura mediadora da interpretação. Dito por outras palavras: a figura da consciência-tarefa, como expressão da natureza cindida da consciência significa a caracterização da consciência como texto, ou seja, como o lugar onde o sentido se manifesta e que exige uma interpretação ${ }^{16}$.

16 Se nos ativermos a esta perspectiva da necessidade de uma mediação interpretativa no acesso ao saber de si da subjectividade, teremos de considerar que no Essai sur Freud se faz a legitimação teórica da prática hermenêutica desenvolvida em La symbolique du mal, onde a reflexão sobre o mal é levada a cabo a partir das expressões culturais onde a consciência religiosa foi deixando os sulcos da sua experiência sobre o mal. Do ponto de vista da legitimação, é Essai sur Freud que assegura a pertinência de La symbolique du mal, permitindo a sua integração cabal no corpus filosófico ricoeuriano. 


\section{O ponto de partida da constituição da figura da consciência-texto: o papel de Husserl}

Husserl desempenha um papel fundamental no conjunto de Essai sur Freud, na medida em que é a partir dos conceitos da fenomenologia que Ricoeur faz a discussão do estatuto epistemológico da psicanálise e torna pensável, no campo de uma filosofia reflexiva, os seus conteúdos. Considero particularmente relevante o facto de a apropriação filosófica da teoria freudiana ser feita através da sua caracterização como uma anti-fenomenologia, por mostrar como Husserl representa o horizonte interpretativo de base. Esta aproximação por contraste entre a psicanálise e a fenomenologia é realizada a partir do papel que o conceito de redução nelas desempenha. Em ambas, reitera Ricoeur, a redução, como atitude metodológica, é fundadora, embora tenha orientações antagónicas em cada uma delas. O modo como a interpreta ao nível da psicanálise, fá-la emergir como anti-fenomenologia, na medida em que o que a psicanálise reduz é, exactamente, a consciência, ou seja, faz com que a consciência se torne problemática em vez de ser o melhor conhecido, destituindo-a, sua posição de origem do sentido:

"Trata-se, portanto, de uma redução, de uma epoquê que muda de direcção (retournée), uma vez que o que inicialmente é o melhor conhecido, o consciente, é suspendido e torna-se o menos conhecido"17.

Neste contexto, Ricoeur ressalta que Freud, ao instituir o inconsciente como lugar substantivo, faz dele o correlato de um "grau zero da reflexão"18, transformando a questão de ser consciente (Bewusstein) na de tornar-se consciente (Bewusstwerden).

Todavia, na minha leitura, a importância de Husserl ressalta, sobremaneira, nesta obra, no momento em que Paul Ricoeur constitui a sua teorização sobre a natureza da subjectividade, pela reelaboração do conceito tradicional de consciência, através da ideia da consciência-tarefa ou da consciência-texto. Este seu trabalho de tematização parte, como se disse antes, do reconhecimento da intrínseca desadequação ou incoincidência da consciência, ou seja, na sua consideração como um texto lacunar, fragmentário e opaco. Ricoeur vai dar forma discursiva a esta situação por intermédio da interrogação Quem sou eu, eu que sou?, cujo significado evidencia que, embora cada um tenha acesso directo à sua existência, contudo, não tem, com a mesma imediatez, acesso ao seu sentido. O sentido da existência de cada sujeito que se interroga é, para si mesmo, problemático. A afirmação do Cogito define uma questão ao mesmo tempo que estabelece uma certeza; isto é, uma reflexão que assenta numa aceitação limitada do Cogito realça a opacidade do existir humano à intuição e, consequentemente, impõe a necessidade de uma estrutura mediadora que possa possibilitar o acesso a esse sentido.

Pode-se, então, dizer que a aceitação limitada do Cogito significa:

a inserção na tradição cartesiana pela aceitação da possibilidade que tem o sujeito de acesso imediato à sua posição na existência e por considerar essa intuição como o ponto de partida irrecusável da reflexão; 
a instauração de um espaço que, sendo impenetrável à intuição, vai obrigar a uma metodologia outra, como via de apropriação do seu si mesmo do sujeito.

Estes dois aspectos, o dado da existência e o problema do seu sentido, radicam no carácter, simultaneamente, apodíctico e não-adequado do Cogito, tal como Husserl o deduz nas Cartesianische Meditationen ${ }^{19}$ e de que Ricoeur se apropria para elaborar a sua posição. Este recurso hermenêutico de Ricoeur legitima-se pela leitura que ele faz desta obra de Husserl, que considera como uma iniciativa no sentido de estabelecer, em Filosofia, o verdadeiro começo ${ }^{20}$. É, então, no horizonte dessa leitura que Ricoeur vai explorar o alcance do Cogito, como começo do filosofar, tal como Husserl o configura na Primeira Meditação.

Husserl estabelece na Primeira Meditação que o eu se capta de forma original e originária, sem que, todavia, essa experiência de captação de si corresponda a uma evidência adequada. Pelo contrário, afirma ele, à vivacidade da presença do eu a si mesmo opõe-se a definição de um horizonte indeterminado. Dai que, para ele, a experiência transcendental do Cogito instaure a simultaneidade de uma certeza de si e de uma limitação constitutiva, no plano do saber, dessa certeza. A posição husserliana determina, por esta via, que o Cogito, que a redução transcendental estabelece, expressa uma evidência apodíctica mas não totalmente adequada. $\mathrm{O} \mathrm{Eu,}$ a que a redução transcendental conduz, apenas na presença viva de si a si mesmo, como existência, é uma evidência adequada. Para lá desse imediato-dado abre-se um horizonte de indeterminação ao qual a evidência intuitiva já não tem acesso ${ }^{21}$. Por outras palavras: a redução transcendental institui a imediatez reflexiva como via de acesso do sujeito a si mesmo, enquanto existência, mas, ao mesmo tempo, implica o reconhecimento da sua limitação porque, também em termos de imediatez, desvenda no sujeito algo opaco a uma evidência adequada.

Ricoeur interpreta esta posição de Husserl salientando:

“A certeza resolvida do 'eu sou' envolve a questão, não-resolvida, da extensão possível da ilusão sobre si mesmo. É nesta falha, nesta não-coincidência entre a certeza do 'eu sou' e a possibilidade da ilusão sobre si, que se pode inserir uma certa problemática do inconsciente" 22 .

19 Edmund HUSSERL, Cartesianische Meditationen und Pariser Vorträge. Husserliana. Gesammelte Werke, Bd. I, 1950. Méditations Cartésiennes, trad. G. Peiffer e E. Levinas, Paris, Vrin, 1953.

20 Cf. Paul RICOEUR, "Étude sur les 'Méditations Cartésiennes' de Husserl”, in À l'école de la phénoménologie, Paris, Vrin, 1986, pp. 161-195. O texto foi publicado inicialmente em 1954.

21 O suporte desta análise assenta no significado de quatro conceitos: evidência, apodicticidade e adequação e não-adequação. A evidência é definida como a via interior, directa e imediata, de acesso à própria coisa. As evidências podem ser perfeitas - ou seja, suficientes - ou imperfeitas - ou seja, insuficientes; as evidências perfeitas ainda se podem subdividir em apodicticas e adequadas. São as evidencias apodicticas que, diz Husserl, se designam por princípios, que podem ser inadequadas. A apreensão directa do Cogito pertence a este último tipo.

22 Paul RICOEUR, De l'interprétation. Essai sur Freud, p. 369. Esta afirmação de Ricoeur é feita no contexto da aproximação entre a psicanálise e a fenomenologia, no quadro da discussão do estatuto epistemológico da psicanálise. 
No entanto, não é apenas através desta obra que Husserl está a sustentar e dar solo legitimador ao diálogo que Ricoeur vai desenvolver com Freud, no horizonte de Hegel e com Hegel, no horizonte de Freud. De um modo geral, a interpretação que faz da temática da redução, bem como o modo como conceptualiza a fenomenologia ${ }^{23}$, levam-no a considerar que esta perspectiva filosófica se inaugura pela instauração de "(...) uma humilhação, uma ferida(...)" na consciência imediata ${ }^{24}$. O próprio conceito de intencionalidade, diz Ricoeur, reitera esta mesma ruptura na serenidade clássica do valor absoluto da presença da consciência a si mesma.

Assim, respaldado na sua interpretação de Husserl, Ricoeur parte da aceitação parcial do Cogito e é no seu horizonte que introduz a necessidade de pensar uma dimensão crítica da subjectividade, ao mesmo tempo que configura a hermenêutica como o processo mediador possível e legítimo no acesso ao saber de si dessa subjectividade. A aceitação limitada do Cogito, nos termos de Husserl, vai dimensionar a questão atrás referida - quem sou eu? -, que o dado eu que sou levanta, como sendo o preenchimento do espaço entre apodicticidade e adequação. A tarefa da reflexão, como hermenêutica, consiste, precisamente, no preenchimento desse espaço, através do desenvolvimento de uma resposta mediata à interrogação quem sou eu, eи que sou? Ricoeur afirma-o, de forma clara:

“(...) a reflexão não é intuição, ou, em termos positivos: a reflexão é o esforço para recuperar o Ego do Ego Cogito no espelho dos seus objectos, das suas obras e, por fim, dos seus actos. (...) Uma filosofia reflexiva é o contrário de uma filosofia do imediato. A primeira verdade - Eu sou, Eu existo - permanece tão abstracta e vazia quanto invencível; é-lhe necessário ser "mediatizada" pelas representações, pelas acções, pelas obras, pelas instituições, pelos monumentos que a objectivizam; é nesses objectos, no sentido mais lato da palavra, que o Ego se deve perder e encontrar-se"25.

Neste texto fica, de facto, claramente explicitado, por um lado, o carácter mediato da única via legítima de acesso ao saber de si próprio e, por outro, que a tessitura cultural é o lugar de passagem necessário dessa mediação. Neste quadro, a metáfora do espelho pode ser interpretada como querendo apontar para três determinações essenciais:
o saber de si é sempre um reconhecimento;
o saber de si só se pode constituir fora do enclausuramento da subjectividade pura;
o saber de si representa uma figura final.

23 Cf., especialmente: Paul RICOEUR, "Introduction a Ideen I de E. Husserl, par le traducteur", in Edmund HUSSER, Idées directrices pour une phénoménologie, trad. Paul Ricoeur, Paris, Gallimard, 1950; "Sur la Phénoménologie", in $\dot{A}$ l'école de la phénoménologie, pp. 141-159; "Kant et Husserl”, in Ibidem, pp. 227-250.

24. Paul RICOEUR, De l'interprétation. Essai sur Freud, p. 368.

25 Paul RICOEUR, De l'interprétation. Essai sur Freud, p. 51. 


\section{O processo de constituição da figura da consciência-texto: $O$ conflito interpretativo entre Freud e Hegel}

A teoria da subjectividade que Ricoeur elabora em Essai sur Freud é o resultado do entrecruzamento de duas hermenêuticas rivais: a psicanálise de Freud e a Phänomenologie des Geistes, de $\mathrm{Hegel}^{26}$. Cada um deles é apropriado por Ricoeur no horizonte do outro, porque cada um deles só ganha, efectivamente, sentido a partir do outro. Contudo, nesse confronto hermenêutico, não desempenham os dois o mesmo papel. Freud representa o contexto interpretativo inicial, porque é no quadro de existência de um inconsciente e em diálogo com ele que Ricoeur salva a consciência, reelaborando uma nova concepção dela. Hegel dará sentido e sequência interpretativa ao processo desencadeado pela hermenêutica psicanalítica. Isto é, o ponto de partida desmistificador da consciência é Freud, mas o seu modelo de inteligibilidade é a ideia de consciência teleológica, tal como Ricoeur a interpreta na Phänomenologie des Geistes, de Hegel.

É no contexto do papel desempenhado por Freud neste processo hermenêutico que Ricoeur pode estabelecer um paralelismo entre o uso que ele faz da psicanálise e o papel da dúvida em Descartes ${ }^{27}$. Dir-se-ia que, no contexto da defesa teórica da ideia de uma consciência falsa, se quer provar, com armas idênticas, que o resultado do assumir crítico da questão da consciência ilusória não é a destruição da consciência, mas sim a necessidade de reformulação do seu conceito, de modo a que possa assumir o inconsciente como seu outro. Da aceitação crítica da hermenêutica desmistificadora, protagonizada pela psicanálise, vai emergir um

26 G. W. Friedrich Hegel, Phänomenologie des Geistes. Sämtliche Werke, Bd. V, Hamburg, Felix Meiner, 1952. La phénoménologie de l'esprit (2 vs), trad. de Jean Hyppolite, Paris, Aubier-Montaigne, s/d. A obra de Hegel directamente convocada para o debate Freud-Hegel é, de facto, a Fenomenologia do espirito. Em relação a Freud, Ricoeur percorre, explicitamente, toda a sua obra, fazendo-o em função do próprio projecto de De l'interprétation. Essai sur Freud. Na verdade, como Ricoeur afirma no seu Avant-propos (p. 8), quer abordar a consistência do discurso freudiano e fá-lo a partir de três tipos de problemáticas:

um primeiro, de natureza epistemológica, centrado na questão da interpretação;

um segundo, directamente recortado das preocupações específicas de uma filosofia reflexiva, assente no objectivo de configurar o tipo de compreensão de si mesmo que a interpretação psicanalítica viabiliza;

um terceiro, de cariz dialéctico, que interroga a exclusividade da psicanálise como interpretação da cultura.

Nessa medida, De l'interprétation. Essai sur Freud realiza dois percursos em torno da obra de Freud. Um percurso de leitura, que segue a evolução dos escritos freudianos (Livro II-Analytique, pp. 67-330), começando pelo texto de Freud de 1895 Esboço de uma psicologia cientifica, que para Ricoeur "représente ce qu'on pourrait appeler un état non herméneutique du système". (p. 79). Um percurso de interpretação filosófica de Freud (Livro III-Dialectique, pp. 331-529), onde se retomam, no plano compreensivo da reflexão filosófica, os textos analisados no Livro II, à luz da intencionalidade problemática da obra no seu conjunto.

Todas as referências bibliográficas de Ricoeur situam os textos de Freud quer na Gesammelte Werke, quer na Standard Edition, quer ainda nas edições publicadas em França.

27 Diz sobre isto Paul Ricoeur em "Herméneutique et psychanalyse", in Le Conflit des Interprétations, p. 172: "Bref, j'use de la psychanalyse como Descartes usait des arguments sceptiques contre le dogmatisme de la chose; mais, cette fois, c'est contre le Cogito lui-même (...)". 
Cogito ferido, mas que, por ter passado pelo crivo da "dúvida", é um Cogito seguro e legitimado.

A passagem por Freud, no processo de reabilitação da consciência, corporiza, exemplarmente, a prática hermenêutica ricoeuriana, por se configurar como um diálogo no próprio terreno teórico e metodológico do outro, na exploração máxima da fecundidade do Conflito de Interpretações. Como se disse, a psicanálise é usada como anti-fenomenologia, ou seja, enquanto processo de redução do Cogito. Nessa medida, a sua apropriação faz-se na linha anti-narcísica de humilhação do Cogito, na sua pretensão de verdade do conhecimento sobre si da subjectividade e, por esse mesmo gesto reflexivo, faz emergir a legitimidade de uma nova problemática sobre o sujeito: a interrogação sobre a sua verdade originária, levantada pela questão quem sou eu, eu que sou? e fundada na diferença entre a apodicticidade e a adequação, na experiência imediata de si, como se viu.

Hegel, com a sua perspectiva teleológica da consciência, como foi referido, é o interlocutor mais imediato de Ricoeur neste diálogo directo com Freud. No meu entender, é o horizonte hegeliano que explica o peso e a forma interpretativa com que Paul Ricoeur se acerca da máxima freudiana Wo Es war, soll Ich werden, no contexto da qual define toda a tarefa psicanalítica bem como o seu sentido.

Ricoeur dá o máximo relevo à referida máxima de Freud, interpretando a psicanálise como uma não-técnica ou mesmo como uma anti-técnica, salientando que o que nela está em jogo é a procura da verdade, no contexto de um percurso que vai de um conhecimento de si imperfeito ao reconhecimento de si, verdadeiro. A ressonância do peso de Hegel na leitura ricoeuriana de Freud vem dada pelo papel atribuído ao reconhecimento em todo o processo interpretativo levado a cabo. Segundo Ricoeur, a psicanálise proporciona a cada sujeito, por um lado, enquanto doutrina, a estrutura teórica interpretativa e, por outro lado, enquanto prática analítica, a situação intersubjectiva, que lhe permitem aceder ao reconhecimento de si mesmo a partir de uma situação inicial de um falso conhecimento sobre si. O tornar-se consciente é, então, um duplo reconhecimento, por ser um reconhecimento de si que se realiza através do reconhecimento de um conhecimento falso de si. Guiado pela sua própria leitura de Hegel, Ricoeur, contudo, não interpreta esse reconhecimento no horizonte de um processo puramente regressivo, determinado pela análise da dinâmica do inconsciente, salientando que a ideia de reconhecimento de falsos-saberes de si, subjacente ao Wo Es war, soll Ich werden, aponta na direcção de uma consciência que só se assume com sentido, no final de uma síntese progressiva. Ou seja, o assumir-se adulto, suposto na máxima freudiana, só é efectivo quando significar um processo de libertação do sujeito das suas determinações traumáticas, abrindo-o à realização plena de si. Ricoeur di-lo assim:

"O sujeito (...) nunca é aquele que se crê. Mas, para que ele aceda ao seu ser verdadeiro, não chega que descubra a inadequação da consciência que toma de si mesmo, nem a força do desejo que o põe na existência. É preciso ainda que descubra que o 'tornar-se consciente', através do qual ele se apropria do sentido da sua existência como desejo e esforço, não lhe pertence, mas pertence ao sentido que nele se faz. É necessário mediatizar a consciência de si pelo espírito, isto é, pelas figuras que fornecem um telos a esse 'tornar-se consciente'." 28 .

Assim, o tornar-se consciente - programa que postula a destruição da coincidência entre consciência e reflexão -, que é a via de acesso ao sentido da 
existência humana, só será significativo quando se dimensionar dentro de um processo de construção-desenvolvimento, constituído pela descoberta de que a forma de se tornar consciente transcende o sujeito, enquanto individualidade determinada. Isto implica que a noção de consciência que Ricoeur elabora em diálogo com a perspectiva freudiana consiste na "(...) capacidade de refazer as figuras do espírito (...)" e "não é a presença a si, a apercepção de um conteúdo (...)"29, instaurando que a dimensão crítica da consciência faz dela uma busca de si.

É, pois, no quadro destas duas hermenêuticas rivais que a figura ricoeuriana da consciência-texto ou da consciência-tarefa se constitui, enquanto interpretação da subjectividade humana, dimensionando-a como o resultado de um processo dialéctico que se desenrola entre um princípio regressivo, um arquê, e um princípio progressivo, um telos, referidos a duas fontes determinadoras: $o$ inconsciente $e$ o espirito, tomadas elas próprias, não como lugares, mas sim como estruturas hermenêuticas.

$\mathrm{O}$ inconsciente, enquanto outro da consciência, é um inconsciente finito $e$ relativo, que se configura e ganha sentido no espaço e no processo de interpretação. Ricoeur recusa ver o inconsciente na perspectiva de um realismo acrítico e, pelo contrário, traça a sua existência reflexiva na relação entre um realismo empírico e um idealismo transcendental. $\mathrm{O}$ inconsciente é estabelecido como o conceito determinante de uma experiência e estruturado nela, por isso, tem de ser definido no campo do cognoscível. Esse é o significado do seu realismo empírico. O objecto de Freud, diz Ricoeur, não é o ser da pulsão, mas sempre já os seus efeitos representativos, dado que a psicanálise é uma semântica do desejo, ou seja, um processo interpretativo da relação entre o desejo e o sentido, tomando como objecto de análise os efeitos de sentido do desejo. Por outro lado, o inconsciente vai emergir no decurso do processo interpretativo. É uma realidade diagnosticada. É este o signifiçado do seu idealismo transcendental.

É desta caracterização dupla do inconsciente que resulta o seu carácter relativo de estrutura hermenêutica. Ricoeur fala de uma relatividade objectiva e de uma relatividade intersubjectiva do inconsciente.

Com a primeira, quer afastar o perigo de se pensar o inconsciente como uma mera projecção subjectiva. A relatividade objectiva do inconsciente significa que ele depende de uma estrutura teórica de descodificação, ao mesmo tempo que aponta para a ideia da não dissociação teoria-método. $\mathrm{O}$ inconsciente, enquanto objecto epistemológico, é estabelecido no interior de uma circularidade hermenêutica.

Com a segunda, quer chamar a atenção para que o inconsciente, enquanto fonte de sentido da existência para um sujeito, se constitui numa situação intersubjectiva. Penso que este aspecto é muito importante para o conjunto do pensamento de Ricoeur, por significar também o rompimento da clausura da subjectividade. $\mathrm{O}$ inconsciente, que no decurso de um processo analítico se constitui, surge, à pessoa analisada, como uma realidade exterior a si. $\mathrm{O}$ duplo reconhecimento no processo de se tornar consciente, de que atrás falava, tem a ver com aceitar o meu falso saber perante a configuração de um novo saber sobre mim, que vem à existência pela interpretação de uma outra pessoa. Ele só terá eficácia quando for reconhecido por mim como saber verdadeiro sobre mim, mas a sua emergência ocorre numa exterioridade em relação a mim mesmo.

A arqueologia é o princípio reflexivo de inteligibilidade de um ser que tem um inconsciente e expressa-se na temática da repetição.

29 Paul RICOEUR, "Herméneutique et psychanalyse", in Le Conflit des Interprétations, p. 120 . 
A arqueologia representa o tema da anterioridade do desejo, estando, por isso, ligada à determinação do sujeito em função de um acontecimento primordial de raiz pulsional. A arqueologia do sujeito aponta para o enraizamento pulsional da subjectividade e para a sua determinação em função desse enraizamento. Está, por isso, ligada ao movimento regressivo de uma teoria do sujeito, ao momento da análise, da decomposição regressiva.

A figura do espírito emerge da interpretação de Hegel e com o mesmo estatuto de estrutura hermenêutica, atribuído ao inconsciente. Parece-me ser lícito dizer que a interpretação de Ricoeur assenta numa perspectiva que, na minha leitura, corresponde a pensar que a consciência e o espírito estão ligados por uma dupla autonomia-dependência.

Diz Paul Ricoeur que, em Hegel, o espírito representa o fim da intencionalidade $^{30}$, ou seja, o nível em que há coincidência entre a existência e a racionalidade, sendo, por oposição, o conceito de consciência sempre assimilado à ideia de consciência infeliz ${ }^{31}$, por ser, essencialmente, busca de si. No entanto, na sua leitura, em Phänomenologie des Geistes, nunca se ultrapassa o plano da intencionalidade, dado que o seu registo discursivo é o da manifestação; a Phänomenologie des Geistes permanecerá uma fenomenologia "do espírito no elemento da consciência" 32 , tanto ao nível da sua primeira parte, em que o desenvolvimento do processo fenomenológico ocorre no plano da subjectividade determinada, como na segunda parte, onde o que se desenrola é a expressão de uma consciência colectiva e histórica. No meu entender, esta leitura de Ricoeur é sustentada pelo texto de Hegel. Na verdade, a Phänomenologie des Geistes narra-nos a configuração fenomenológica do espírito a partir do lugar onde ele se manifesta, que é a consciência natural, acontecendo pelo desenvolvimento desta. É essa narrativa que faz emergir a génese do saber de si do espírito, como processo de realização de si, sendo a partir da consciência - como lugar da manifestação -, que vai ser mostrado esse processo de concreção ${ }^{33}$. É este aspecto que designo como a dupla autonomia relativa entre a consciência e o espírito. Penso que a Phänomenologie des Geistes nos mostra, ao mesmo tempo e em interdependência mútua, a concreção do espírito - enquanto realidade que comporta em si a necessidade do seu desenvolvimento como forma de realização -, e o desenvolvimento de uma consciência que é, em si mesma, cisão e inquietação e, por isso, movimento de superação de si como consciência. É por esta via, que interpreto o sentido da figura do Saber Absoluto no final da obra como sendo o saber da dupla autonomia-dependência entre a consciência e o espírito. Nesta medida:

do ponto de vista da consciência, o Saber Absoluto é reconciliação. De facto, com a figura do Saber Absoluto a consciência deixa de ser

30 Cf. Paul RICOEUR, "Hegel et Husserl sur l'intersubjectivité", in Phénoménologies hegelienne et husserlienne. Les classes sociales selon Marx, Paris, Centre Nationale de la Recherche Scientifique, 1981, pp. 5-17, especialmente, pp. 6, 7, 8. Cf. Ibidem, p. 7.

32 Ibidem, pp. 5-6.

33 Penso que Hegel pode legitimar esta interpretação:

1. pela análise que faz do espírito e dos seus graus de desenvolvimento, nos parágrafos 381-387 da Enciclopédia, análise essa que nos permite entender a Fenomenologia do Espírito como um momento desse desenvolvimento;

2. pela demonstração que faz, na II parte do "Prefácio" à Fenomenologia do Espirito, Das Absolute ist Subjekt, da necessidade que tem a Ciência de se realizar como consciência de si, através do desenvolvimento da consciência natural. 
cisão e negatividade ${ }^{34}$, porque acede ao reconhecimento da sua própria essência, ou seja, reconhece que nela a manifestação é igual à essência, ou que aquilo que ela diferencia de si como seu outro, como consciência, é, afinal, ela própria. Na figura do Saber Absoluto a consciência supera a sua visão unilateral de consciência e, por isso, o que nessa visão unilateral the surgia como o seu objecto aparecer-lhe-á como a manifestação do carácter reflexivo da própria substância, uma vez que no Saber Absoluto a certeza da consciência iguala a sua verdade. Na minha perspectiva, isto significa que o acesso da consciência à sua essência consiste no reconhecimento da sua autonomia relativa, porque ela verá a substância como si mesmo, mas esse si mesmo como uma manifestação do absoluto.

Do ponto de vista do espirito, o Saber Absoluto é rememoração.

O Saber Absoluto é a última figura do espírito, aquela em que ele realiza o seu conceito, ou seja, se sabe a si mesmo como espírito. É a figura em que o espírito toma consciência de si. Ora, o conteúdo dessa figura é efectivamente constituído pela rememoração de todo o processo da sua própria constituição, sendo, por isso, a rememoração de um duplo processo:

por um lado, da espiritualização do objecto, em que se descreve como o objecto se foi des-objectivando, realizando-se como um si mesmo, figura que assume na forma da religião;

por outro, da substancialização da consciência, em que se descreve como a consciência se busca a si mesma na alteridade e se vai reconhecendo nela através daquilo que se poderia chamar a acção em geral.

Assim sendo, a consciência de si do espírito que o Saber Absoluto realiza é o saber do processo pelo qual o espírito configura o seu conceito, processo esse que ocorre na consciência e através da sua dialéctica, ou seja, da experiência que a consciência faz sobre si mesma. É por essa razão que também, nesta segunda perspectiva, o Saber Absoluto me parece explicitar a autonomia-dependência do espírito, em relação à consciência. Ele trata, a meu ver, da inevitabilidade da relação dialéctica entre o finito e o infinito ${ }^{35}$.

A teleologia é, por sua vez, o princípio de inteligibilidade de uma consciência pensada numa relação de interdependência com a noção de espírito, significando que a libertação total da consciência se dá no sentido de uma síntese progressiva, através da sua abertura ao futuro e à história.

Arqueologia e teleologia representam, então, dois princípios antagónicos. Um, a arqueologia, apontando para o aspecto determinado da subjectividade

34 Cf., fundamentalmente o parágrafo 17 da "Introdução" à Fenomenologia do Espírito.

35 A minha análise assenta, sobretudo nos parágrafos 1-13 do Capítulo sobre o Saber Absoluto da Fenomenologia do Espirito e B. ROUSSET, "Introdução" e Comentário à sua tradução do capítulo sobre o Saber Absoluto, in G. W. F. HEGEL, Le Savoir Absolu, Paris, Aubier-Montaigne, s/d, pp. 7-85 e 123-246. Embora, em Essai sur Freud, Ricoeur não tematize o conceito de espírito, como faz com o de inconsciente, as teorização que leva a cabo para configurar o conceito de teleologia, sustentam a leitura que propus, baseada noutros textos seus, mostrando que, para ele, consciência e espirito são duas realidades interdependentes. Cito, como exemplo, uma definição de espírito (p. 447): “(...) l'esprit, le Geist, c'est ce mouvement, cette dialectique des figures qui de la conscience fait une 'conscience de soi', une 'raison' et finalement, à la faveur du mouvement circulaire de la dialectique, reafirme la conscience immédiate, mais à la lumière du procès complet de la médiation". 
humana, através da sua subordinação a uma raiz pulsional. O outro, a teleologia, que indica a abertura do sujeito para a realização de si, para a imaginação de possibilidades de ser. Um explica em função do passado; o outro em função do futuro.

Contudo, para Ricoeur, trata-se de mostrar que há entre eles uma relação dialéctica e não apenas antinómica, ou seja, que há em Freud uma teleologia não tematizada e em Hegel uma arqueologia suposta. Só desse modo, arqueologia e teleologia podem representar os princípios de inteligibilidade de uma consciência-texto, explicitando-a como o lugar onde emergem, em relação dialéctica, a determinação e a liberdade. Para Ricoeur, Hegel e Freud encontram-se na importância que ambos atribuem ao desejo na construção da cultura, bem como o valor que dão ao papel da perda do objecto, do trabalho do luto, na educação do desejo.

Para demonstrar que a questão de Freud está em Hegel, Ricoeur propõe uma interpretação do Capítulo IV da Phänomenologie des Geistes, onde se desenvolve a génese da consciência de si, explicitando que ela assenta "(...)na insuperabilidade da vida e do desejo (...)"36. É nesse contexto que faz emergir o carácter dialéctico da teleologia. A sua argumentação centra-se na tese de que a realização teleológica da consciência de si, a constituição do seu si mesmo, se faz sobre o que chama superados insuperáveis - a vida e o desejo -, realizando-se através da análise do processo do reconhecimento, como operação de génese da consciência de si. A estratégia argumentativa abre-se em duas teses:

o reconhecimento é a explicitação e o desenvolvimento do desejo e não uma operação exterior em relação à estrutura desejante da consciência

A estrutura desejante da consciência expressa, realmente, a sua natureza cindida e inquieta de consciência, porque, por um lado, significa que vê o outro como diferente de si e, por outro, que se procura a si própria nesse outro que quer suprimir. Ou seja, o desejo expressa a natureza teleológica da consciência, mostrando-a como movimento que regressa a si a partir do que não é ela e, ao mesmo tempo, também a mostra como emissor não seguro de si, em termos de verdade, uma vez que, sendo a essência do desejo a supressão do objecto, aponta para a necessidade que a consciência tem de suprimir o seu outro para ser segura de si. Para Ricoeur é do próprio desenvolvimento dessa estrutura que o reconhecimento ganha corpo, porque ele é o resultado do desejo do outro em que o desenrolar da consciência-desejo termina.

O reconhecimento é uma luta e toda essa luta se trava no elemento da vida.

O reconhecimento, enquanto operação bilateral, é uma luta de morte, não só por ser travada até à morte por uma das consciências de si envolvidas, como também por ser uma luta abandonada com medo da morte, pela outra consciência de si. Por essa razão, enquanto operação de génese para si mesma da consciência de si, é uma luta pela vida. É, pois, no seio da vida que o reconhecimento emerge e se desenrola o seu sentido. É o facto de as consciências de si valorizarem a vida de forma diferente que determina um reconhecimento desigual ou unilateral, situação que remete, de novo, para a problemática do desejo. O senhor, a consciência de si vitoriosa, pode satisfazer o desejo em 
si mesmo, na sua estrutura de ambiguidade, através da consciência de si vencida: o escravo. Para isso este vai ter de reelaborar a constituição desejante da sua consciência. O escravo vai ter de reprimir o seu desejo para satisfazer o desejo do senhor, sendo desta situação que decorre uma outra estrutura intencional da consciência de si que é o trabalho. O trabalho é a resposta do servo que ocorre no contexto do medo e se desenvolve numa dupla direcção: servir o senhor e dar saída à estrutura desejante da consciência de si. $\mathrm{O}$ trabalho vai-se transformar no elemento de mediação do efectivo reconhecimento da consciência de si, porque só ele vai permitir a permanência da subjectividade e da objectividade nessa operação de génese. Através do trabalho, o escravo transforma o mundo e é nele, no mundo transformado, que reconhece a sua subjectividade. Pelo trabalho, o retorno a si, por ser feito pelo reconhecimento de si no objecto produzido, já não se dá pela supressão do objecto, como no desejo, mas, pelo contrário, através da sua permanência.

Ricoeur interpreta todo este processo pondo em relevo a sua estrutura originária. A sua tese consiste em considerar que o desenvolvimento teleológico da consciência se dá pela conservação-superação do arcaísmo desejo-vida, considerando que o facto originário da conscência, o seu acontecimento primordial, é a sua dimensão pulsional-desejante ${ }^{37}$. Por esta via, afirmará a ressonância da questão freudiana em Hegel, salientando a presença permanente do desejo "(...) no próprio coração do processo 'espiritual' (...)"38 de formação da consciência.

37 Penso que esta interpretação de Ricoeur não é absolutamente compossível com a teorização de Hegel sobre a consciência, nem sequer com o seu tratamento ao nível da totalidade da Fenomenologia do Espírito, desprezando, pelo menos, três questões fundamentais:

1. não considera a análise do "Prefácio" à Fenomenologia do Espírito, quando Hegel explicita a origem da natureza cindida da consciência, análise essa que contextualiza os parágrafos 5-17 da "Introdução", no que respeita a esta temática. Todos estes textos convergem no sentido do parágrafo 413 da Enciclopédia, que é o de considerar a consciência como manifestação, como reflexão do espírito, contexto que explica a inquietude e a negatividade da natureza da consciência. Segundo estes textos, a natureza cindida da consciência, factor determinador do seu desenvolvimento teleológico, vem-lhe do carácter reflectido da própria natureza da substância de que é manifestação. Assim, o acontecimento primordial da consciência é, pois, a sua autonomia relativa em relação ao absoluto de que ela é um momento de concreção. De onde, haverá na Fenomenologia do Espírito a afirmação do primado do fim, da realização da essência da consciência na figura do Saber Absoluto, na qual terá lugar a reconciliação consciência-consciência de si;

2. não faz intervir na sua argumentação o facto de, em Hegel, o Saber Absoluto ser uma figura terminal que, enquanto realização da consciência, significa que ela se reconhece como manifestação do espírito. Ou seja, o conceito de teleologia que Ricoeur manipula não é, como em Hegel, o de uma teleologia infinita que supõe um desenvolvimento não residual e postula a plenitude racional, mas sim um desenvolvimento encerrado numa circularidade hermenêutica, privilegiando o movimento infinito da dialéctica;

3. por fim, não autonomiza o trabalho como estrutura de mediação do único reconhecimento efectivo, prendendo-o demasiado às condições da sua emergência e não lhe dando o papel que, a meu ver, no sentido de acção em geral, ele desempenha no desenvolvimento de toda a Fenomenologia do Espírito.

38 Paul RICOEUR, De l'interprétation. Essai sur Freud, p. 453. 
No que respeita à identificação da questão hegeliana em Freud, a estratégia argumentativa de Ricoeur é menos localizada e mais globalizante, sendo sua finalidade encontrar uma teleologia implícita no freudismo, com base em três tipos de indicadores ${ }^{39}$ :

em primeiro lugar, nos conceitos operatórios de Freud, isto é, aqueles que ele usa sem tematizar e que correspondem àquilo que permite distinguir a psicanálise, quer da psicologia em geral, quer da fenomenologia, convergindo na consideração do campo psicanalítico como um relação intersubjectiva. Neste aspecto verá Ricoeur um imenso eco de Hegel, salientando a semelhança do processo analítico com a dialéctica do senhor e do servo e com a temática do reconhecimento;

em segundo lugar, em outros conceitos, como o de identificação, que, embora tematizados, são discordantes no quadro conceptual geral da psicanálise. Para Ricoeur, a questão da identificação não se deixa entender apenas através da marca regressiva da perda de objecto.

por fim, no que designa como problemas não-resolvidos, ressaltando, como exemplar, a questão da sublimação.

No meu entender, em qualquer dos casos, o fundamento da argumentação reside em salientar que a psicanálise não cobra sentido pleno apenas na dimensão regressiva em que se quer movimentar. $\mathrm{O}$ seu esforço argumentativo consiste, por isso, na procura de configuração da teoria freudiana como uma discursividade mista, onde força e sentido se entrelaçam, ou seja, em que regressão e prospecção se dialectizam:

"É preciso (...) supor, em sentido contrário ao movimento regressivo, do qual a psicanálise faz a teoria, uma capacidade para a progressão, que a prática analítica desenvolve, mas que a teoria não tematiza"40.

Por outro lado, o esforço argumentativo de Ricoeur assenta na importância que atribui à máxima freudiana Wo Es war, soll Ich werden que, como já referi, representa a sua chave de leitura de toda a psicanálise. Sobre isto diz:

"É, finalmente, a própria tarefa de se tornar eu que, no seu princípio, é irredutível à economia do desejo, na qual se inscreve. Mas esta tarefa permanece o não-dito da doutrina freudiana; o conceito vazio de sublimação é o último símbolo desse não-dito (...)"41 .

\section{Notas finais}

Independentemente dos reparos críticos de que é passível a argumentação ricoeuriana acerca da consciência, em Essai sur Freud, uma coisa se me afigura como importante e incontestável - o seu esforço hermenêutico para trazer à ribalta da prática filosófica questões controversas e, por vezes, malditas.

Esse esforço, que constitui uma das marcas do seu pensar, dá conta, por um lado, da tenacidade da sua meditação - que nunca desiste de procurar o sentido 
profundo da própria actividade reflexiva -, por outro, da orientação decisivamente hermenêutica da sua actividade filosófica - que busca, paulatinamente, nos textos da tradição, aquilo que ele mesmo designa como as possibilidades não-exploradas do passado, para ir legitimando velhos temas à luz das suas mais novas problemáticas - e, por fim, põe em evidência que, para ele, o novo, em filosofia, é sempre contextualizável e só no plano da relação sedimentação-inovação cobra a sua dimensão própria, que é a historicidade.

A intertextualidade que marca o seu estilo próprio, enquanto autor, é a expressão substantiva da presença da alteridade no seu pensar pessoal e, ao mesmo tempo, da profunda vontade de sentido que dirige todo o seu labor filosófico. 
